\title{
OLNEY SÃO PAULO: BREVES ASPECTOS DA PESQUISA SOBRE O PERCURSO DO CINEASTA
}

\author{
Claudio Cledson Novaes ${ }^{1}$ \\ Mírian Sumica Carneiro Reis ${ }^{2}$
}

\begin{abstract}
Resumo: Este artigo propõe algumas reflexões derivadas da pesquisa realizada sobre a obra de Olney São Paulo e apresenta seu percurso, bem como alguns resultados das articulações teóricas e críticas que os pesquisadores do Núcleo de Estudos em Literatura e Cinema (NELCI/UEFS) agenciam para discutir a obra deste escritor e cineasta.

Palavras-Chave: Olney São Paulo; Cinema; Literatura.
\end{abstract}

\begin{abstract}
This article proposes some reflections derived from research about the work of Olney São Paulo, and presents some results of theoretical and critical articulations that researches at the Núcleo de Estudos em Literatura e Cinema (NELCI/UEFS) agencies to discuss the work of this writer and filmmaker.
\end{abstract}

Key Words: Olney São Paulo; Cinema; Literature.

Analisamos, neste artigo, a concepção da pesquisa sobre Olney São Paulo, discutindo os aspectos do projeto desenvolvido no Núcleo de Estudos em Literatura e Cinema, da UEFS, que tem a perspectiva de reconstituir a trajetória do cineasta pelos caminhos da história cultural brasileira contemporânea. Além disso, a nossa pesquisa se propõe também a desdobrar criticamente alguns episódios éticos e estéticos do seu cinema atravessado por outros campos de linguagens, como a história, a literatura popular e erudita, a música e as artes plásticas que situam a produção cinematográfi-

1 Doutor em Teorias da Comunicação pela Escola de Comunicação da Universidade de São Paulo (ECA-USP); Professor Titular da Universidade Estadual de Feira de Santana (UEFS); coordenador do Núcleo de Estudos Literatura e Cinema (NELCI); pesquisador do Programa de Pós-Graduação em Literatura e Diversidade Cultural (PPGLDC/UEFS), onde desenvolve projetos de pesquisa financiados pela FAPESB/CNPq; dentre outros, é autor de $\mathrm{Ci}$ nema sertanejo: o sertão no olho do dragão (2005), co-organizador, com Marcos Botelho, de Seis passeios por Cidade de Deus (2007) e, com Licia Soares de Souza e Roberto H. Seidel, de Figuras da violência moderna: confluências Brasil/Canadá (2010). Endereço eletrônico: ccnovaes.uefs@gmail.com. Doutoranda em Ciência da Literatura (Teoria Literária) na Universidade Federal do Rio de Janeiro (UFRJ); Mestre em Literatura e Diversidade Cultural pela Universidade Estadual de Feira de Santana (UEFS); Bolsista CAPES. Endereço eletrônico: miriansumica@gmail.com. 
ca de Olney no "entre-lugar" da intencionalidade realista de cunho documental e da experimentação ficcional na sua cinematografia.

Constitui-se como um traço singular do estilo na obra de Olney São Paulo o componente emblemático da sua formação entre o cinema clássico e o moderno, assim como a partir de elementos da literatura modernista e dos escritores e intelectuais concretistas seus contemporâneos. O nosso projeto mapeou esta dinâmica híbrida na formação e na produção do cineasta e chegou a uma coletânea de artigos para a publicação em livro.

Problematizamos neste artigo o objetivo de cada capítulo do livro, projetando um olhar sobre determinado aspecto da obra de Olney São Paulo e traduzindo as etapas da pesquisa, através de referências que permitam o entendimento do leitor sobre uma produção ainda pouco estudada sistematicamente no cenário acadêmico da cultura brasileira, como é o caso da obra de Olney São Paulo.

O projeto sobre Olney é parte dos nossos estudos sobre as relações entre literatura e cinema no Brasil, desenvolvidos pelo Núcleo de Estudos em Literatura e Cinema - NELCl, da Universidade Estadual de Feira de Santana, Bahia, correspondendo ao quarto livro publicado pela Coleção Corisco. Os textos a serem publicados no livro são produtos do projeto de pesquisa financiado pela FAPESB, que teve como um dos seus desdobramentos a realização de estágio de Pós-Doutorado na Escola de Comunicação da Universidade Federal do Rio de Janeiro - ECO-UFRJ. O conjunto de textos reflete o estágio atual das pesquisas realizadas por professores e estudantes vinculados ao NELCl sobre a obra de Olney São Paulo, analisando documentos encontrados em acervos locais, nacionais e estrangeiros, além de trazerem a público algumas referências coletadas em entrevistas realizadas com especialistas da literatura e do cinema sobre o cineasta.

No primeiro momento da pesquisa, discutimos, através de correspondências escritas e recebidas por Olney, o capital simbólico do jovem artista da provinciana Feira de Santana dos anos 1950, cidade em vias de tornar-se um pólo econômico do Estado, devido a sua estratégica localização no cruzamento rodoviário Norte-Sul do território nacional. Neste período, Olney desperta para arte do século XX, como todo menino do interior, a partir das sessões das clássicas salas de cinema.

Imediatamente, Olney começa a circular em meio aos cineastas locais, através do Clube de Cinema da Bahia, e nacionais, que transitam pelo interior do Estado rodando obras que seriam os primeiros filmes modernos 
do Brasil, constituindo o ciclo do cinema baiano que, segundo alguns críticos, se encerraria com a obra do próprio Olney, Grito da Terra (1964).

A sua formação inicial neste contexto é obtida principalmente através da leitura dos livros modernistas e dos manuais do cinema clássico. Mas também, em grande parte, a sua entrada no cinema dá-se pela praxis de sonhos e expectativas que ilustram as mentes dos jovens engajados no cinema como discurso nacional-popular à época.

O imperativo de entrar na vida intelectual leva Olney a escrever duas cartas emblemáticas nos anos 1950: uma endereçada ao escritor baiano Jorge Amado, agitador da cultura nacional e perpétuo defensor de artistas em todas as áreas da cultura; e outra enviada ao importante crítico e articulador do movimento pré-cinemanovista no Brasil, Alex Viany.

Os dois correspondentes de Olney São Paulo atuavam em movimentos da política cultural brasileira e respondiam pelos editoriais de jornais que tinham forte influência na formação intelectual dos jovens da época. Tanto Amado quanto Viany movimentam discussões sobre a arte, a cultura e a política de um período sob a égide do Realismo Socialista, em contrapontos aos ideais estéticos e engajamentos do Partido Comunista. Em nome do nacionalismo na arte, eles redigiam jornais, manifestos e boletins, como o "Para Todos" e "O Jornal de Cinema", aos quais estão endereçadas as cartas de Olney aos dois correspondentes.

Amado e Viany, para além da contribuição das suas obras no cenário cultural e artístico brasileiro, também estavam completamente empenhados nos embates políticos e culturais da época. Alex Viany relembra a ação do Deputado Jorge Amado no momento em que as discussões sobre a estruturação de uma indústria do cinema no Brasil ganhavam tons de debates intelectuais e gestões políticas memoráveis. Viany registra em seu livro Introdução ao Cinema Brasileiro que:

Assim, quando do I Congresso Nacional de Cinema Brasileiro, o Legislativo acabava de receber a versão Cavalcanti do Instituto Nacional de Cinema. 0 projeto original datava de 1946, propunha um Conselho Nacional de Cinema, e fora apresentado pelo deputado Jorge Amado. Mais tarde, ficara sob o patrocínio de vários outros deputados, como Brígido Tinoco e João Café Filho (VIANY, 1993, p. 110).

Como podemos perceber, as ações organizadoras dos congressos e as ações políticas legislativas dos dois intelectuais partem do estatuto de mero espetáculo clássico e transitam para o território político do cinema. A indús- 
tria cinematográfica torna-se assunto de Estado nas efervescentes discussões dos intelectuais que preparam o advento do Cinema Novo.

Neste sentido de transformação política e cultural do cinema, o mais sensível na leitura das cartas enviadas para Olney aos dois guias intelectuais da época é a percepção geral destes movimentos e o objetivo de formação através das correspondências entre intelectuais e seus seguidores, associando ao caráter especulativo da arte o senso pragmático de inserção na indústria cultural, conforme Olney repete nas cartas aos dois interlocutores, dizendo-se ser um jovem com "inclinação invulgar para o cinema".

Após acompanhar o ingresso do cineasta na carreira cinematográfica, o passo seguinte da nossa pesquisa foi fazer uma análise sobre os documentos que registram um dos acontecimentos mais traumáticos do cinema brasileiro envolvendo Olney: o filme Manhã Cinzenta (1969), que se torna um dos mais emblemáticos casos para se investigar as tensões da dialética arte-política neste período.

A definição topológica do "estado de exceção" de Giorgio Agambem (2004) traz um viés teórico importante para entendermos esta perspectiva da ação da censura do regime militar sobre este filme. Segundo o autor:

Longe de responder a uma lacuna normativa, o estado de exceção apresentase como a abertura fictícia no ordenamento, com o objetivo de salvaguardar a existência da norma e sua aplicabilidade à situação normal. A lacuna não é interna à lei, mas diz respeito à sua relação com a realidade, à possibilidade mesma de sua aplicação. É como se o direito contivesse uma fratura essencial entre o estabelecimento da norma e sua aplicação e que, em caso extremo, só pudesse ser preenchida pelo estado de exceção, ou seja, criando-se uma área onde essa aplicação é suspensa, mas onde a lei, enquanto tal, permanece em vigor (AGAMBEN, 2004, p. 48-49).

Nessa abertura fictícia do ordenamento, as medidas tomadas pelo Estado assumem uma força-de-lei corroborada pela aparente manutenção da lei, em prol de um bem social de uma realidade também ficcionalizada pelas propagandas ideológicas, distantes da experiência concreta, palpável, de cada um. $\mathrm{O}$ conceito acima pode ser identificado no personagem autoritário do filme de Olney representado pelo robô: ele é responsável pelo interrogatório que condena à morte os jovens subversivos. Este personagem cria a "lei" e é, simultaneamente, criado por ela, o que torna o Estado e o censor uma espécie de configuração única que se traduz no oxímoro do "êxtase-pertencimento", conceito desenvolvido por Agambem (2004), que demonstra o desvio do sentido de poder quando há uma ditadura pela força. 
A síntese vanguardista do filme Manhã Cinzenta (1969) é a dialética do lírico versus o grotesco, quando os personagens emergem de discursos inflamados e em corpos dançantes num mundo-palco "administrado" pela frieza racional de robôs. É uma obra de ambivalência crítica entre as estéticas das vanguardas modernistas, os modelos clássicos de representação realista e as novas gerações da narrativa nacionalista popular.

Outro paradoxo desta narrativa é a recepção sem censura do conto/roteiro de Manhã Cinzenta, escrito em 1966, e publicado no mesmo ano do filme, em 1969, criando um contraponto com a restrição da censura ao filme, quando a escritura literária é publicada sem cortes. Isto aponta para as contradições da violência da censura na interdição do filme, considerando o cenário de tensão na história da cultura brasileira e os embates políticos entre o regime militar instaurado pelo golpe e as perspectivas críticas do cinema moderno.

Neste sentido, Roberto Schwarz (1978), num estudo clássico, apesar de já revisado por ele em algumas publicações mais recentes, propõe alguns esquemas ainda instigantes para sistematizarmos o transe políticocultural e ideológico do período, principalmente a sua tese de que a esquerda, apesar da repressão política, manteve certa hegemonia no campo da cultura. Para ele, "o artista buscaria a sua força e modernidade na etapa presente da vida nacional, e guardaria quanta independência fosse possível em face do aparelho tecnológico e econômico, em última análise, sempre orientado pelo inimigo" (SCHWARZ, 1978, p. 76-77).

O próprio Olney, no texto escrito para o interrogatório no processo militar ao qual foi intimado a depor por causa do filme Manhã Cinzenta, aborda a questão contraditória na recepção do tema de seu filme originado do conto de mesmo nome. Ele tenta explicar a percepção da sua obra sobre a temática abordada e explicita os equívocos que levaram à apreensão do material filmográfico e à sua prisão por suposto envolvimento com os movimentos subversivos. Neste documento escrito para o inquérito na Aeronáutica, disponível na Cinemateca do Museu de Arte Contemporânea do Rio de Janeiro, Olney São Paulo, entre outras declarações, nega ter responsabilidade direta sobre a origem da cópia do seu filme exibida no avião sequestrado pelo MR-8 e desviado para Cuba; confirma ainda que reproduziu várias cópias, mas que estas foram enviadas para fora do país com o intuito de participar em festivais de cinema.

Enfim, no depoimento, Olney descreve o que considera a problemática central do seu filme, ou seja: "o filme tinha um sentido puramente hu- 
manista [grifo do autor] e cultural de forma moderna, talvez dentro de uma 'lógica do absurdo' se podia conceber, representava um estado de espírito de um casal [...]".

Após o acontecimento emblemático com o filme Manhã Cinzenta, Olney São Paulo transforma a sua carreira de cineasta em documentarista com inserções quase sempre traumáticas no cinema de ficção.

Nesta direção, investigamos os contornos entre as questões do cinema nacional e do cinema documental no mundo, através dos diálogos possíveis entre filme O Ditame de Rude Almajesto: Sinais de Chuva (1976), realizado por Olney a partir da adaptação de uma crônica do escritor Eurico Alves sobre o imaginário sertanejo em torno dos mitos da chuva, analisando-o em contraponto aos filmes Eu, um negro (1958), do cineasta e etnógrafo francês Jean Rouch, e Pour la suite du monde (1962), do cineasta canadense Pierre Perrault.

A partir da problemática do conceito de representação no documentário, comparamos o discurso cinematográfico nos documentários de Rouch, Perrault e Olney, analisando aspectos do audiovisual etnográfico e discutindo as estratégias dos três diretores ao filmarem sujeitos subalternos colonizados e confinados na geopolítica clássica do discurso colonizador. Analisamos como eles recriam nos filmes as vozes comunitárias, dando novas formas literárias e literais às representações culturais, ao construírem um discurso audiovisual para além da tecnologia discursiva colonialista do viajante descobridor. Eles desconstroem a percepção clássica da etnografia dominante sobre os territórios identitários do Sertão, do Quebec e da África. Nos três universos cinematográficos, o francês, o canadense e o brasileiro, interpretamos a singularidade de cada cinematografia, estabelecendo o contraponto das semelhanças discursivas sobre os três territórios culturais diferentes, buscando a unidade de linguagem do cinema moderno na diversidade do documentário etnográfico.

Na nossa pesquisa, observamos que o cineasta e escritor Olney São Paulo está para a crítica da arte no Brasil como uma "imagem brumosa" semelhante ao seu filme Manhã Cinzenta (1969), que foi perseguido pela censura e interditado do cenário da cultura nacional. Mas, por outro lado, no aspecto do documentário, identificamos a sua permanência latente na provocação artística de um imaginário com discursos de preservação do patrimônio cultural brasileiro.

Um passo importante na nossa pesquisa foi discutir a construção discursiva da mídia sobre a trajetória da obra de Olney. Para isto buscamos, 
através de notícias de jornais, compreender o olhar da recepção crítica na análise da sua obra ao calor dos lançamentos principalmente dos seus filmes de longa metragem em ficção.

Esta análise dos artigos publicados em jornais pelo Brasil desvelou aspectos da memória cultural brasileira sobre o esquecimento de obras à margem da história, bem como alguns dilemas pessoais e políticos da vida do escritor e cineasta Olney São Paulo, que espelham um espetáculo, ao mesmo tempo, humano e lírico, e desumano e tenebroso, observando-se as relações e embates entre ele e a crítica profissional.

Antes de iniciarmos a nossa pesquisa a ser publicada em livro, desconhecíamos grande parte da história da obra de Olney no cenário da arte nacional, principalmente por dentro do ponto de vista da recepção crítica. Tínhamos o conhecimento da sua trajetória através de algumas informações do senso comum e do jargão intelectual e, principalmente, através de registros superficiais sobre ele encontrados na ainda frágil historiografia do cinema brasileiro.

Por isto, resolvemos percorrer outros caminhos por dentro da crítica feita à sua obra, coordenando o projeto de pesquisa acadêmica que nos levou à curiosidade de revisitar certas circunstâncias da obra de Olney em sua travessia pelo território real e imaginário da crítica institucionalizada do cinema no Brasil, destacadamente aquela produzida no período bastante emblemático da nossa política cultural, ou seja, entre os anos 1960-70.

As informações frágeis e lacunares da nossa informação sobre Olney São Paulo, anterior a este projeto de pesquisa, dificultavam o entendimento de alguns mecanismos de recepção da sua obra pelos críticos durante o período de resistência e de contracultura no cenário da ditadura militar.

Até hoje, algumas instituições acadêmicas e pensamentos intelectuais ainda recalcam lampejos diferentes em nome do cânone estabelecido pela modernidade. Mas a relação entre a contracultura e os discursos historiográficos já assentados nos discursos oficiais, mesmo os discursos dos movimentos revolucionários já assimilados, deve ser problematizada, como é o caso da situação tensa da obra de Olney no fogo cruzado entre a crítica cinematográfica tradicionalista e os cinemanovistas.

A estratégia metodológica que adotamos para ler a crítica feita pelos jornalistas de cultura cinematográfica à obra de Olney foi estabelecer o lugar de fala dos críticos no âmbito do projeto do Cinema Novo em contraponto com o discurso de um cineasta, ao mesmo tempo, precursor e à margem deste movimento de política cinematográfica no Brasil. Com este 
pressuposto definido, passamos a analisar vários comentários de jornais de todo o Brasil sobre Olney São Paulo, no capítulo do livro que dedicamos a sua recepção crítica.

Quanto à produção literária de Olney São Paulo, analisamos os mecanismos de estruturas cinematográficas em seus contos e novelas, como no caso de $A$ antevéspera. Neste e outros textos, Olney cria imagens que estilizam a noção de tempo sintético, possibilitado a linguagem subverter a noção de temporalidade contínua e de consequências evolutivas, conforme se apresenta como revolução temporal na linguagem de simultaneidade do cinema.

A narrativa do conto de Olney cria uma atmosfera de terror e mistério, construindo um narrador comprometido com a crítica da realidade trágica das guerras do momento contemporâneo ao século XX; ou mais radicalmente, quando o conto faz analogias sutis entre as guerras reais e cinematográficas e os estados militarizados contemporâneos, como é o caso das ditaduras.

As analogias de Olney iconizam os referentes quando seus signos literários traduzem outros ícones da literatura e do cinema historicamente localizados nos extremos de tempos e cultura ocidentais e orientais. Por isso, a sua narrativa absorve desde Shakespeare a Kurosawa, através do imaginário que os leitores armazenam das obras literárias e cinematográficas, sintetizando memórias de tempos históricos e realidades culturais opostas, mas complementares no jogo estético da suplementaridade diacrônica e sincrônica, na forma como Olney se apropria dos autores: o teatrólogo inglês, no auge do renascimento, com suas reflexões sobre a tirania e as paixões da cultura ocidental, e o cineasta japonês, refletindo a partir do seu século XX sobre as clivagens históricas, que são simultaneamente as mesmas dores, apesar das diferentes interpretações culturais.

Na perspectiva do narrador de $A$ antevéspera, as imagens literárias ou cinematográficas no discurso intersemiótico se reorganizam no suporte literário do conto, ao ser publicado em livro para ser lido pelo receptor e não assistido como um filme. Por outro lado, a fissura na forma literária, aberta pelo aspecto de roteiro explícito ou implícito no estilo do autor, desloca a leitura do conto para uma versão intersemiótica que vai além da escrita verbal. Não há uma tradução de identidade entre as imagens, mas sim uma citação do cinema na literatura em estado de choque, como diz Julio Plaza sobre "o projeto tradutor criativo [que] define-se assim pelos 
conflitos, atritos e roteiros ambíguos dos seus interpretantes" (PLAZA, 2008, p. 35).

Vejamos um fragmento do conto:

Amém.

Amém aos homens: pais filhos, também ao Espírito Santo. Jamais aos cegos e aleijados porque estes dizem amém e deles é o Reino dos Céus - um trono manchado de sangue sem espectros de Shakespeare ou de Kurosawa. No trono do Sol nascente o som haverá de derreter a terra, em seu dia de juízo. Um dia, em que o som transformará os homens, as mulheres, as crianças e os dinossauros, em uma só poeira só, compacta, azul-cinérea e lilás (SÃO PAULO, 1969, p. 38).

O imaginário cinematográfico representado no texto escrito de Olney do fragmento acima remete ao que Pasolini define como escritura intersemiótica: aquela que revitaliza os diálogos entre linguagens, assim como a realidade é revitalizada na representação das imagens no cinema.

Discutindo este conceito de tradução intersemiótica, a partir do problema sugerido pelo cineasta italiano, Carlos da Silva Sobra, em seu artigo "Pasolini - reflexões sobre uma tradução intersemiótica" ${ }^{3}$, conclui que:

Trata-se, portanto, dos esquemas primordiais de um código cinematográfico, entendido como reprodução convencional da realidade. Quando colocamos em prática o aparato imagístico da recordação, projetamos no interior de nosso cérebro seqüências fílmicas pequenas ou grandes, contínuas ou entrecortadas, sinuosas ou lineares, que objetivam representar imagisticamente a realidade. Dessa forma, pode-se dizer que tais arquétipos de reprodução da linguagem da ação, ou melhor, da realidade (que em última instância é sempre a ação) estariam amalgamados num meio mecânico e comum: o cinema. Através dessa ótica, pode-se afirmar que o cinema representa não apenas um momento scritto de uma língua natural e total, mas a ação da realidade. O cinema é a linguagem da ação, o signo dinâmico, um código comunicativo que segue a mesma mecânica de representação utilizada pela língua escrita em contraponto à língua oral.

Outro traço importante da obra literária de Olney é o desvio dentro da tradição regionalista da história literária brasileira, que é necessário verificar no contexto da produção do autor contextualizado na euforia da reivenção do Nordeste através do imaginário do cinema brasileiro à época.

Na segunda metade do século XX, os recursos do cinema na literatura apontavam para a novidade da imagem-movimento influenciando os recursos narrativos literários, após a adaptação da literatura popular e do mo-

3 Disponível em: http://www.filologia.org.br/vicnlf/anais/caderno05-12.html.

Cláudio Cledson Novaes, Fernanda Aguiar C. Martins, Roberto H. Seidel (Org.) 
derno romance realista/naturalista ter sido a base de popularização do cinema. Isto no Brasil deu-se, principalmente, com o tema regionalista, que movimentou várias adaptações que consolidaram o sucesso da indústria do cinema clássico brasileiro com os melodramas realistas populares da literatura do século XIX e XX adaptados aos filmes. Mas este mesmo tema regionalista renasce nas novas experiências do neo-realismo, tanto literário quando fílmico, como é o caso de escritores como Guimarães Rosa e o filmes emblemáticos do movimento cinemanovista.

Estes pressupostos iniciais, ao relacionarmos cinema e literatura, são importantes para compreendermos a tradição e a ruptura entre a narrativa realista e os movimentos neo-realistas na obra de Olney São Paulo.

O novo paradigma é sugerido através dos sentidos polifônicos das novas narrativas, após o modernismo. Mas este olhar é intensificado a partir da segunda metade do século $X X$, período em que os escritores e cineastas se defrontam com vários dilemas sociais, econômicos, políticos e psicológicos entranhados na estética e na ética envolvida no jogo entre o sentimento local e o desenraizamento universal, resultado que se configura no nomadismo global potencializado nas imagens locais da estética da migração.

Esta sensibilidade mobiliza toda uma geração de escritores e diretores envolvidos direta e indiretamente nos movimentos nacionalistas do chamado "regionalismo sertanejo". A questão de engajamento político neste tema é importante, mas o fundamental é a disposição para um modernismo crítico na forma que produz o cenário de uma nova subjetividade nacional, ao se explicitar as consequentes transformações estilísticas nas narrativas diante do novo contexto político e cultural do país. Representamse novos personagens em crise dos valores tradicionais e fragmenta-se a totalidade do real numa linguagem de estéticas construtivistas e concretistas que lançam olhares novos sobre os temas do cotidiano. Por exemplo, os novos modelos regionalistas que transitam entre o local e o universal de maneira mais problematizada desta dicotomia clássica do modernismo, desmistificando esta noção simplificada de fronteiras com arranjos fixos e dicotômicos. Como observa Homi Bhabha (2005, p. 21):

Os embates de fronteira acerca da diferença cultural têm tanta possibilidade de serem consensuais quanto conflituosos; podem confundir nossas definições de tradição e modernidade, realinhar as fronteiras habituais entre o público e o privado, o alto e o baixo, assim como desafiar as expectativas normativas de desenvolvimento e progresso. 
Os escritores e cineastas lançam mãos de estratégias discursivas que deslocam as fronteiras das linguagens, das ciências, dos estilos e dos próprios artefatos artísticos: livro, roteiro, filme, arranjos. Nessa tensão, o escritor intensifica a prática da interpelação artística do mundo pela lógica da cultura, ao invés do movimento estético pelo dogma da ideologia política. Ele provoca a negação do heroi identificado com o épico moderno que espelhava o gosto da classe média.

A literatura e o cinema de Olney seguem o caminho do neo-realismo literário em busca de formas de narrar que desestabilizem o movimento clássico fruto do mesmo gosto político burguês conservador. Isto desencadeia a estética narrativa chamado por Gilles Deleuze (1992, p. 78) de imagem-tempo: aquele que faz o espectador pensar sobre o movimento, porque dele nasce "uma nova raça de personagens".

Finalizamos os estudos a ser publicados em livro analisando outro aspecto fundamental em diálogo com a obra de Olney: o imaginário da cultura popular com a arte brasileira. Para, para além das relações entre literatura e cinema, os temas eruditos e populares, as artes plásticas e a literatura popular confirmam o imaginário de um autor que se tornou nacional ao articular os temas e estilos locais em sua obra em constante movimento.

Em um dos seus contos de tema sertanejo, o cenário da vila e da região da caatinga é o foco central da narrativa. Ele descreve o momento de espera de um Destacamento que mudará a rotina estática do cenário e em movimento cinematográfico, o foco narrativo mostra as pessoas e a natureza personificada na expectativa de uma epopeia de sangue e luta entre os soldados e os cangaceiros. Por causa do esperado embate, a ambiência do conto traz as marcas da violência fundadora da mitologia do imaginário de crueldade no sertão, imagem que se liga rapidamente a outros imaginários primitivos construídos nas narrativas de invenção deste lócus geopolítico e cultural, que é constituído de logos em raros instantes, como as rápidas paradas do trem na estação narradas no conto de Olney: "A estação, parada rápida do trem que vai e vem de Juazeiro, é a meia légua de distância. Uma meia légua daquelas contadas em vara-braça, no esmorecer do sol".

As narrativas das ações em cada capítulo do conto seguem este estilo cinematográfico lírico e trágico de Olney e nos remetem ao seu imaginário popular singularizado pela vocação deste cineasta dublé de escritor. É da cinematografia que ele apreende as formas de montagem e os movimentos de ação dos herois e bandidos dos saloons do velho western nos filmes americanos, outra tradição popular presente em seu imaginário. Após arti- 
cular os eventos apropriados dos dois imaginários - o popular nordestino e o cinema clássico - , o conto Destacamento, rebatizado de Cravo Santo numa publicação em formato de livreto de Cordel, chega ao desfecho quando a ideologia do leitor se defronta com o inusitado jogo de escondeesconde do personagem-narrador, bem ao jeito da memória popular, o que possibilita a leitura dos desvios nos sentidos ideológicos da narrativa segundo a opção do leitor neste jogo político da luta entre as forças do Estado e o cangaço.

A espera absurda e a angústia do por vir em Destacamento apresentam-se como um diálogo com Esperando Godot, de Samuel Beckett, escrita e publicada entre 1948 e 1950, em que duas pessoas esperam por um homem (ou uma solução, ou novas utopias no contexto devastador do pósguerra, ou mesmo uma justificativa minimamente possível para os horrores legados a povos arrasados) que não chega. O viés cômico e alegórico da obra becketiana influenciou muito da geração de Olney, pois reforça o teor de absurdo em ter esperança quando valores, ideologias, experiência sensível estão dilacerados. No conto de Olney, o teor trágico resgatado do imaginário sobre a ferocidade dos embates entre cangaço e Estado não diminui o absurdo quase sisifiano de repetir a espera(ança).

O espetáculo da narrativa neo-realista inspirada no imaginário do sertão revive na forma os contrastes e contradições de um conteúdo social emblemático. Conforme Rui Facó, os dilemas sociais do sertão experimentados na ficção já se verificam na tradição de se atribuir a ao fenômeno da violência sertaneja brasileira o atributo de subversão ou de bandidagem, desde a Guerra de Canudos. Segundo ele, "muito antes do advento da República, o Conselheiro já pregava 'doutrinas subversivas', na opinião da vigilante cúpula eclesiástica, e já existia de sua parte 'receio de grandes desgraças', segundo as autoridades civis" (FACÓ, 2009, p. 97).

Em nossa pesquisa investigamos outros aspectos fundamentais do diálogo de Olney São Paulo com a cultura popular sertaneja e com a potência dos sentidos plásticos da narrativa em relação as suas referências literárias e cinematográficas tomadas contraponto com a obra de artistas plásticos como o também feirense Raimundo de Oliveira.

Olney costumava registrar em seus depoimentos que algumas das fontes principais do seu imaginário popular eram as figurações plásticas dos personagens populares pintados por Raimundo. Ambos os artistas conviveram em dois ambientes muito emblemáticos: primeiro, a juventude dos dois mergulhados nas experiências da cultura popular tradicional que o 
sertão brasileiro canalizou para a Feira de Santana através de materiais e símbolos presentes tanto nos quadros do pintor, quanto desvelados nas primeiras fotografias cinematográficas e imagens literárias de Olney; o segundo momento de convivência dos dois foi no ambiente urbano e intelectual metropolitano do Rio de Janeiro, onde, de certa forma, ambos aparecem como indivíduos deslocados, que transferem para a arte os transtornos e desconfortos deste imaginário urbano.

Os elementos mais contundentes na plástica de Raimundo de Oliveira são os temas da mitologia trágica de seus personagens populares e a forma expressionista das suas pinceladas. Estes dois elementos: o imaginário popular - principalmente os mitos religiosos - e os aspectos do expressionismo, predominam também na escritura literária e cinematográfica de Olney São Paulo. Por exemplo, a novela $A$ transcendente anunciação da Rosa traz desde o título os traços deste diálogo entre o escritor e o pintor feirense, que se assemelham tanto nos aspectos da produção artística quanto na biografia trágica de ambos. As atribulações pessoais de Raimundo Oliveira tão intensamente traduzidas nas imagens de suas telas o levam a antecipar o fim da vida, ativando a via do suicídio para escapar do absurdo do mundo.

Olney também traduz em seus textos e imagens o martírio popular que, em grande parte, pertenceu a sua trajetória de vida. E, mesmo apesar de ele não ter literalmente posto fim à sua vida, o seu desfecho simboliza facilmente esta associação do ser dilacerado no mundo absurdo, e a sua morte pode até ser associada a uma espécie de suicídio, tão bruscos foram seus confrontos com as adversidades e com a imagem de certo desapego ao imediato, quase trocando a vida material pela transcendência, como se lê em seus personagens. Os dois artistas traduzem este imaginário pessoal nas formas da arte moderna brasileira, como dois anjos expulsos do cânone nas relações tortuosas entre suas vidas e obras e a crítica.

Enfim, traçamos neste artigo a trajetória da nossa pesquisa sobre Olney, a qual estruturou a proposta de publicação do livro de ensaios sobre vários aspectos da sua obra, no sentido de trazer aos leitores acadêmicos e a outros admiradores da literatura e, principalmente, do cinema nacional, alguns aspectos que sobressaem na análise mais sistemática da obra deste sertanejo-urbano, jacuipense, feirense, baiano, carioca e brasileiro, artista do mundo, Olney São Paulo. 


\section{REFERÊNCIAS}

AGAMBEM, Giorgio. Estado de exceção. Trad. Iraci D. Politi. São Paulo: Boitempo, 2004. Col. Estado de Sítio.

ARENDT, Hannah. Sobre a violência. Trad. André Duarte. Rio de Janeiro: Civ. Brasileira, 1994.

ALBUQUERQUE JR., Durval Muniz de. A invenção do nordeste e outras artes. Recife: Fundação Joaquim Nabuco; São Paulo: Cortez, 2001.

AMADO, Jorge. Tereza Batista Cansada de Guerra. [Romance]. São Paulo: Martins, 1972.

AUTRAN, Arthur. Alex Viany: crítico e historiador. São Paulo/Rio de Janeiro: Perspectiva/Petrobrás, 2003. Col. Debates - Cinema.

AVELLAR, José Carlos. A ponte clandestina - teorias de cinema na América Latina, Birri, Glauber, Solanas, Garcia Espinosa, Sanjines, Alea. São Paulo: Editora 34, 1995.

BARTHES, Roland. O grau zero da escrita. Trad. Mário Laranjeira. São Paulo: Martins Fontes, 2000.

BAKHTIN, Mikhail. A cultura popular na Idade Média e no Renascimento - contexto de François Rabelais. Trad. Yara Frateschi. São Paulo/Brasília: EDUNB/Hucitec, 1993.

BAZIN, André. Qu'est-ce que le cinema? Paris: Les Editions do Cerf, 7ạ ART, 2002.

BHABHA, Homi K. O local da cultura. 3. reimp. Trad. Mirian Ávila et al. Belo Horizonte: UFMG, 2005.

BOSI, Ecléa. Cultura de massa e cultura popular - leituras operárias. Rio de Janeiro: Vozes, 1978.

BOSI, Alfredo. Reflexões sobre a arte. São Paulo: Ática, 1986.

BENJAMIN, Walter. Obras escolhidas - magia e técnica, arte e política. 7. ed. Trad. Sérgio P. Rouanet. São Paulo: Brasiliense, 1994. Vol. 1.

CARVALHO, Maria do Socorro Silva. A nova onda baiana: cinema na Bahia (1958/1962). Salvador: EDUFBA, 2003.

CANDIDO, Antonio. Literatura e sociedade. São Paulo: Publifolha, 2000.

DA-RIN, Sílvio. Espelho partido - tradição e transformação do documentário. Rio de Janeiro: Azougue, 2006.

DELEUZE, Gilles. A imagem-tempo - cinema II. Trad. Eloisa de A. Ribeiro. São Paulo: Brasiliense, 2005.

DELEUZE, Gilles. Conversações. Trad. Peter Pál Pelbart. Rio de Janeiro: Editora 34, 1992.

DESJARDINS, Denys. (Coord.). L'Oeuvre de Pierre Perrault - La trilogie de L'île-aux-Coudres - textes e témoignages. Montreal: ONF/NFB, 2007.

DUARTE, Eduardo de Assis. Jorge Amado: romance em tempo de utopia. Rio de Janeiro: Record/UFRN, 1996.

EISENSTEIN, Sergei. O sentido do filme. Rio de Janeiro: Zahar Ed., 2002.

FACÓ, Rui. Cangaceiros e fanáticos - gênese e luta. Rio de Janeiro: UFRJ, 2009.

FOUCAULT, Michel. As palavras e as coisas. Trad. Salma Muchail. São Paulo: Martins Fontes, 1995.

140 Número temático: literatura e cinema. A Cor das Letras - UEFS, n. 11, 2010 
GOMES, Paulo Emílio Sales. Cinema: trajetória no subdesenvolvimento. 2. ed. Rio de Janeiro: Paz e Terra, 1980.

HALL, Stuart. Da diáspora - identidades e mediações culturais. Liv Sovik. (Org.). Trad. Adelaine G. Resende et al. Belo Horizonte/Brasília: UFMG/UNESCO-BR, 2003.

JOSÉ, Ângela. Olney São Paulo - A peleja do cinema sertanejo. Rio de Janeiro: Quartet, 1999.

LEITE, Ciro de Carvalho. Grito da terra - Caatinga. Rio de Janeiro: Ed. Lux, 1964.

LIMA, Luiz Costa. (Org.). A literatura e o leitor - textos de estética da recepção. Rio de Janeiro: Paz e Terra, 2002.

MACIEL, Neila Dourado Gonçalves. Raimundo de Oliveira: um místico entre os modernos. Anais do 19o Encontro da Associação Nacional de Pesquisadores em Artes Plásticas "Entre Territórios" - 20 a 25/09/2010 - Cachoeira - Bahia - Brasil.

MARSOLAIS, Gilles. L'Aventure du Cinema Direct Revisitée. Québec : Laval, Cinéma, Les 400 coups, 1997.

MARTIN-BARBERO, Jesús. Dos meios às mediações - comunicação, cultura e hegemonia. 2. ed. Trad. Ronaldo Polito e Sérgio Alcides. Rio de Janeiro: UFRJ, 2003.

MICELI, Sérgio. Intelectuais à brasileira. São Paulo: Companhia das Letras, 2001.

PLAZA, Julio. Tradução intersemiótica. São Paulo: Perspectiva. Col. Estudos, 2008.

RAMA, Ángel. Literatura, cultura e sociedade na América Latina. Trad. Rômulo Monte Alto. Belo Horizonte/MG: ED. UFMG, 2008. Col. Humanitas.

RAMOS, Fernão Pessoa. (Org.). Teoria contemporânea do cinema - documentário e narrativa ficcional. São Paulo: Senac, 2005, v. II.

RAMOS, José Mário Ortiz. Cinema estado e lutas culturais - anos 50/60/70. Rio de Janeiro: Paz e Terra, 1983.

RICOEUR, Paul. A memória, a história, o esquecimento. Trad. Alain François et al. Campinas: Ed. UNICAMP, 2007.

ROCHA, Glauber. Revisão crítica do cinema brasileiro. São Paulo: Cosac \& Naify, 2003.

ROCHA, Glauber. Revolução do Cinema Novo. São Paulo: Cosac \& Naify, 2004.

SAID, Edward W. Representações do intelectual - as conferências Reith de 1993. Trad. Milton Hatoum. São Paulo: Companhia das Letras, 2005.

SCHWARZ, Roberto. O pai de família - e outros estudos. Rio de Janeiro: Paz e Terra, 1978.

SANTIAGO, Silviano. Vale quanto pesa: ensaios sobre questões político-culturais. Rio de Janeiro: Paz e Terra, 1982.

SANTIAGO, Silviano. Nas malhas da letra - ensaios. Rio de Janeiro: Rocco, 2002.

SANTOS, Francisco Alves dos. Cinema brasileiro 1975 - entrevistas com cineastas brasileiros. Curitiba: Edições Paiol; Fundação Cultural de Curitiba, 1975.

SÃO PAULO, Olney. A antevéspera e o canto do sol - contos e novelas. Rio de Janeiro: José Álvaro Editor, 1969.

SARTRE, Jean-Paul. Que é a literatura. 3. ed. Trad. Carlos Felipe Moisés. São Paulo: Ática, 2004. 
SIMÕES, Inimá. Roteiro da intolerância - a censura cinematográfica no Brasil. São Paulo: SENAC, 1999.

VIANY, Alex. O processo do cinema novo. Org. José Carlos Avellar. Rio de Janeiro: Aeroplano, 1999.

VIANY, Alex. Introdução ao cinema brasileiro. Rio de Janeiro: Revan, 1993.

XAVIER, Ismail. Cinema moderno brasileiro. 3. ed. São Paulo: Paz e Terra, 2001.

XAVIER, Ismail. O discurso cinematográfico - a opacidade e a transparência. São Paulo: Paz e Terra, 2005.

ZUMTHOR, Paul. Escritura e nomadismo. Trad. Jerusa Pires e Sonia Queiroz. São Paulo: Ateliê, 2005. 